\title{
Pengaruh Jumlah Lapisan Terhadap Reflection Loss pada Komposit Barium Heksaferit / Polianilin sebagai RAM (Radar Absorbing
}

\author{
Material) \\ Lita Nurricha Wahyuni, Widyastuti dan Rindang Fajarin. \\ Jurusan Teknik Material dan Metalurgi, Fakultas Teknologi Industri, Institut Teknologi Sepuluh \\ Nopember (ITS) \\ J1. Arief Rahman Hakim, Surabaya 60111 Indonesia \\ e-mail: wiwid@mat-eng.its.ac.id
}

\begin{abstract}
Abstrak-Penelitian Radar Absorbing Material (RAM) kali ini bertujuan untuk membuat Polymer Matrix Composite (PMC) dengan reinforce berupa Barium Heksaferit sebagai bahan magnetik dan matriks polimer PAni sebagai bahan dielektrik. Pembuatan komposit ini bertujuan untuk meningkatkan kualitas dari RAM. Komposit RAM disintesis dengan metode polimerisasi in situ. Komposit RAM tersebut dilapiskan pada baja kapal grade A tipe AH36 dengan metode Dallenbach layer, ketebalan $6 \mathbf{m m}$ dengan variasi jumlah lapisan single layer, double layer dan multilayer. Analisa terhadap ikatan kimia, sifat konduktivitas listrik, struktur mikro dan sifat reflection loss dari komposit RAM dilakukan dengan pengujian FTIR, LCR-meter, SEM dan VNA. Dari hasil penelitian, diperoleh bahwa penyerapan paling optimal pada jumah lapisan multilayer dengan reflection loss sebesar $49,028 \mathrm{~dB}$ pada frekuensi penyerapan $8,2 \mathrm{GHz}$.
\end{abstract}

Kata kunci-Dallenbach layer, jumlah lapisan, Polianilin

\section{PENDAHULUAN}

$\mathrm{S}$ ALAH satu teknologi pertahanan yang dapat meningkatkan kemampuan armada kapal perang ialah kapal siluman. Teknologi kapal siluman merupakan teknologi yang membuat kapal tidak terdeteksi oleh Radar. Kapal siluman dikembangkan melalui dua cara, yakni RAS (Radar Absorbing Structure) dimana rekayasa terletak pada desain sudut kapal dan RAM (Radar Absorbing Material) dengan merekayasa material yang digunakan pada lapisan kapal.

Barium Heksaferit mempunyai sifat kemagnetan dengan tingkat kestabilan tinggi terhadap pengaruh medan magnet luar pada suhu Barium Hexaferrite banyak dipilih dalam berbagai aplikasi yang berhubungan dengan sifat kemagnetan terutama pada Radar Absorbing Material (RAM). Dari aplikasi Barium Heksaferit, telah banyak pula dilakukan penelitian tentang penggunaan polimer konduktif pada aplikasi RAM. Berdasarkan penelitian [1] yang telah dilakukan, RAM terbuat dari 2 bahan utama yaitu material dielektrik dan material magnetik. Apabila dipadukan akan menghasilkan penyerapan yang paling optimum.

Polimer konduktif sendiri adalah material yang mempunyai konduktivitas tinggi dengan mengatur tingkat konsentrasi doping [2]. Jenis Polimer yang memiliki sifat termal yang baik dan konduktivitas yang tinggi antara lain adalah Polianilin (PAni). Material polimer jenis ini jika dibandingkan dengan polimer konduktif lainnya adalah lebih mudah disintesis baik secara kimia maupun elektrokimia [3].

Jenis Polimer yang memiliki sifat termal yang baik dan konduktivitas yang tinggi antara lain adalah Polianilin (PAni). Sebelumnya telah ada beberapa penelitian yang telah di lakukan [4], telah mensintesis Barium Hexaferrite menggunakan metode sol-gel dan komposit BaM/PAni menggunakan metode polimerisasi in situ dengan variasi rasio berat $(\mathrm{PAni} / \mathrm{BaM}=1 / 2,1 / 1,2 / 1)$ yang menghasilkan reflection loss optimum pada $2 / 1$ yaitu $-12 \mathrm{~dB}$ dengan frekuensi $21.5 \mathrm{GHz}$.

Untuk tujuan penyerapan dengan minimum refleksi dan pita penyerapan yang lebar, impedansi medium gelombang datang harus sesuai dengan impedansi material penyerap. Selain itu, gelombang elektromagnetik yang masuk ke dalam material dapat dilemahkan dan diserap material dengan ketebalan tertentu. Penyerap dengan jumlah lapisan single layer tidak dapat optimal dalam menghasilkan minimum refleksi dengan pita yang lebar. Oleh karena itu, perlu dikembangkan jumlah lapisan double layer dan multilayer. Penelitian sebelumnya [5] berhasil memperluas pita penyerapan dan meningkatkan rugi refleksi dengan jumlah lapisan double layer menggunakan material komposit BaM dari pasir besi/PAni. Sedangkan penelitian Nuraini [6] berhasil memperluas pita penyerapan dan meningkatkan rugi refleksi dengan jumlah lapisan Multilayer menggunakan material komposit Hematit/PAni. Pada penelitian kali ini, metode yang digunakan adalah polimerisasi in situ. Dengan menggunakan metode tersebut, terdapat beberapa kelebihan seperti reagen yang dipakai lebih mudah didapat dan lebih hemat energi. Perhatian utama pada penelitian ini ditujukan pada jumlah lapisan terhadap reflection loss dari gelombang mikro pada komposit RAM.

\section{METODE PENELITIAN}

\section{A. Material}

Pada penelitian kali ini digunakan Barium Heksaferrit sebagai material magnetik. Hal ini dikarenakan Barium Heksaferit mempunyai sifat magnetic yang tinggi dan stabil, sehingga cocok diaplikasikan sebagai penyerap radar. Sedangkan Polianilin dan Carbon black digunakan sebagai material dielektrik dikarenakan nilai konduktivitasnya yang cukup tinggi, sehingga dapat membantu penyerapan gelombang elektromagnetik dari radar. Barium Heksaferit 
yang digunakan diperoleh dari sintesis dengan metode solgel. Untuk mensintesis komposit BaM/PAni dilakukan proses polimerisasi in situ dimana bahan-bahan yang digunakan adalah serbuk Barium Heksaferit, monomer (anilin), DBSA Dodecylbenzene Sulfonic Acid $\left(\mathrm{C}_{18} \mathrm{H}_{30} \mathrm{O}_{3} \mathrm{~S}\right)$, Amonium Peroksidisulfa $\left(\left(\mathrm{NH}_{4}\right)_{2} \mathrm{~S}_{2} \mathrm{O}_{8}\right)$, Aseton, Aquades.

\section{B. Sintesis Barium Heksaferit/Polianilin}

Proses sintesis komposit pada penelitian ini menggunakan metode polimerisasi in situ. Perbandingan yang digunakan antara Barium Heksaferrit dengan Monomer (Anilin) adalah $3: 7$. Anilin yang diperoleh dalam bentuk monomer dengan wujud cair berwarna coklat bening ditambahkan dengan DBSA yang berwujud cair dengan warna bening sebagai dopan asam protonik sebanyak 2,3 gram yang kemudian dilarutkan menggunakan aquades, kemudian larutan tersebut diaduk menggunakan magnetic stirrer selama 15 menit sampai warnanya menjadi putih keruh dan mengeluarkan busa. Setelah itu, ditambahkan serbuk Barium Heksaferit yang berwarna hitam dan dilakukan pengadukan menggunakan magnetic stirrer selama 15 menit hingga warnanya menjadi hitam keruh, dilanjutkan dengan penambahan APS yang berwujud cair bening dan telah diencerkan dengan aqudes sebagai inisiator atau oksidator dalam proses polimerisasi sebanyak 2,8 gram. Penambahan APS tersebut dilakukan pada lingkungan dengan temperatur $\sim 0^{\circ} \mathrm{C}$, selanjutnya proses pengadukan dilakukan selama 8 jam dengan temperatur $\sim 0^{\circ} \mathrm{C}$. Setelah proses pengadukan selama 8 jam, akan terbentuk endapan berwarna hijau yang selanjutnya akan disaring menggunakan kertas penyaring. Kemudian, endapan tersebut akan dicuci menggunakan larutan aceton dan aquades. Setelah dicuci, endapan tersebut dikeringkan diatas permukaan kaca selama \pm 24 jam. Selanjutnya, endapan yang kering dihaluskan dan terbentuk serbuk komposit RAM (BaM/PAni) yang berwarna hijau tua.

\section{Proses Pelapisan}

Serbuk komposit berwarna hijau tua yang terbentuk, selanjutnya dicampurkan dengan cat epoxy berwarna abuabu yang kemudian akan dilapiskan pada baja grade A tipe AH36. Sebelum dilapisi dengan material RAM, baja terlebih dahulu dipreparasi sesuai standar sampel pengujian VNA. Perbandingan massa komposit dengan cat epoxy sebesar 1 : 9. Sedangkan pada jumlah lapisan double layer dan multilayer ditambahkan serbuk carbon black yang berwarna hitam dengan komposisi 30wt\% dari komposit RAM (BaM/PAni). Selanjutnya, cat, RAM dan carbon black yang sudah tercampur dilapiskan pada baja sesuai variasi ketebalan lapisan dan jumlah lapisan yang telah ditentukan. Setelah itu, proses pengeringan lapisan cat + komposit RAM selama \pm 3 hari.

\section{Karakterisasi}

Untuk mengetahui karakteristik dari material komposit RAM, maka dilakukan beberapa karakterisasi, yakni pengujian SEM-EDX yang digunakan untuk mengetahui morfologi dan kandungan unsur yang ada pada BaM, PAni, $\mathrm{CB}$, komposit BaM/PAni, Komposit BaM/PAni yang ditambahkan $\mathrm{CB}$, dan hasil pelapisan (single layer, double layer dan multilayer), selanjutnya FTIR untuk mengetahui ikatan apa saja yang terbentuk pada polimer PAni, BaM, $\mathrm{CB}$, komposit BaM/PAni dan komposit BaM/PAni yang ditambahkan CB, lalu LCR-meter untuk mengetahui nilai konduktivitas listrik dari masing-masing material (PAni, komposit BaM/PAni, Carbon black, Komposit + CB) dan VNA digunkan untuk mengetahui nilai reflection loss pada masing-masing spesimen.

\section{HASIL DAN DISKUSI}

\section{A. Hasil Pengujian SEM-EDX}

Pengujian SEM kali ini dilakukan pada 5 sampel untuk karakterisasi awal, yakni BaM, PAni, komposit BaM/PAni (Barium Heksaferrit/Polianilin), Carbon black dan Komposit BaM/PAni + CB. Pada Gambar 1 menampilkan hasil dari pengujian SEM dengan beberapa perbesaran. Gambar 1c menunjukkan morfologi dari komposit BaM/PAni, pada gambar tersebut memperlihatkan bentuk morfologi dari $\mathrm{BaM} / \mathrm{PAni}$ yang berupa globular. Partikel BaM terlihat pada morfologi komposit BaM/PAni yaitu berbentuk heksagonal dan poligonal. Sementara itu, terdapat beberapa kabut yang merupakan aglomerasi pada permukaan komposit BaM/PAni Hal ini disebabkan adanya sisa pelarut saat proses polimerisasi [7]. Pada Gambar 1c dan Gambar 1d menunjukkan bahwa $\mathrm{CB}$ mempunyai morfologi berbentuk serpih atau flake.
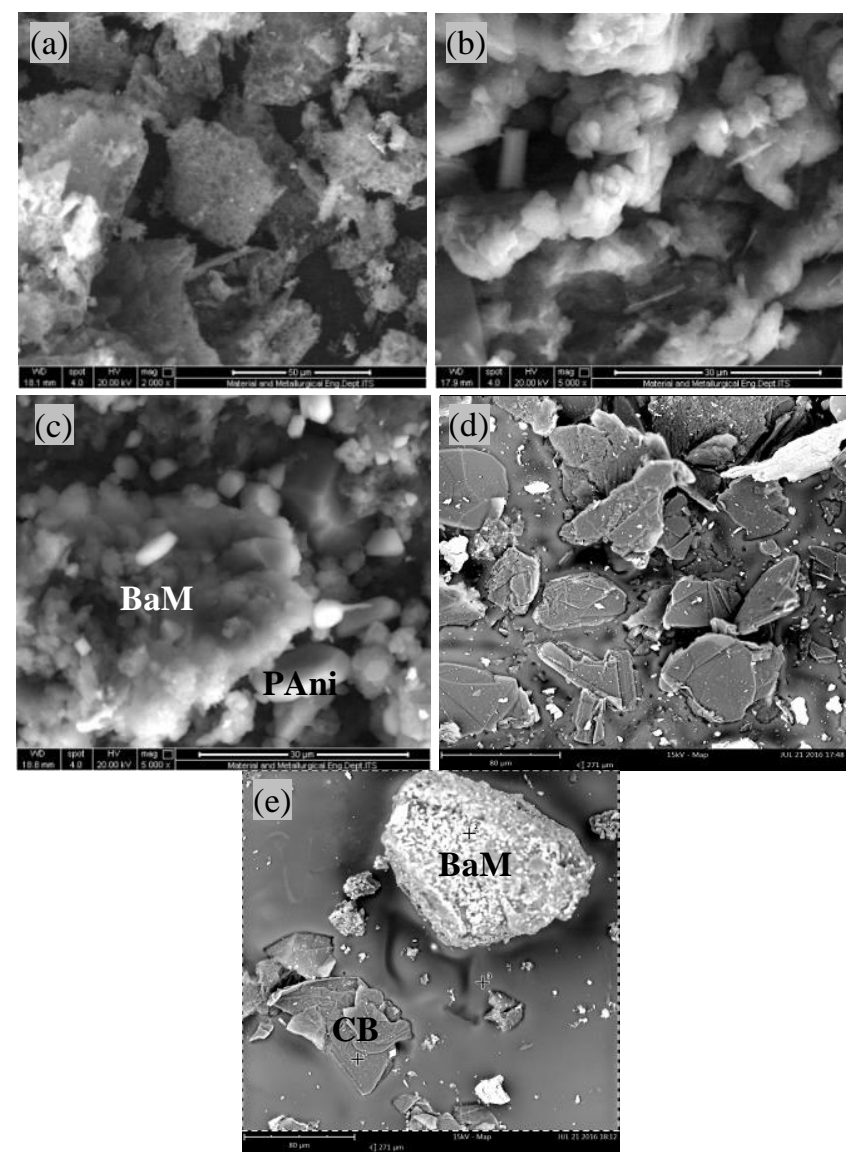

Gambar 1. Hasil Pengujian SEM (a) BaM Perbesaran 2000x, (b) PAn perbesaran 5000x, (c) BaM/PAni perbesaran 5000x, (d) Carbon black perbesaran 1000x dan (e) BaM/PAni + CB perbesaran 3000x.

Pengujian SEM dengan perbesaran 3000X juga dilakukan pada masing-masing material yang telah dicampur dengan cat epoxy dan kemudian dilapisakan pada baja kapal. Gambar 4.4a merupakan morfologi pada lapisan single layer dimana pengujian SEM dilakukan pada satu titik, Gambar 2b sampai Gambar 2d menunjukkan morfologi dari lapisan double layer dimana dilakukan pengujian SEM pada 3 titik. Dan pada Gambar 2e sampai Gambar 2i menunjukkan 
morfologi dari lapisan multilayer yang dilakukan pengujian SEM pada 5 titik.
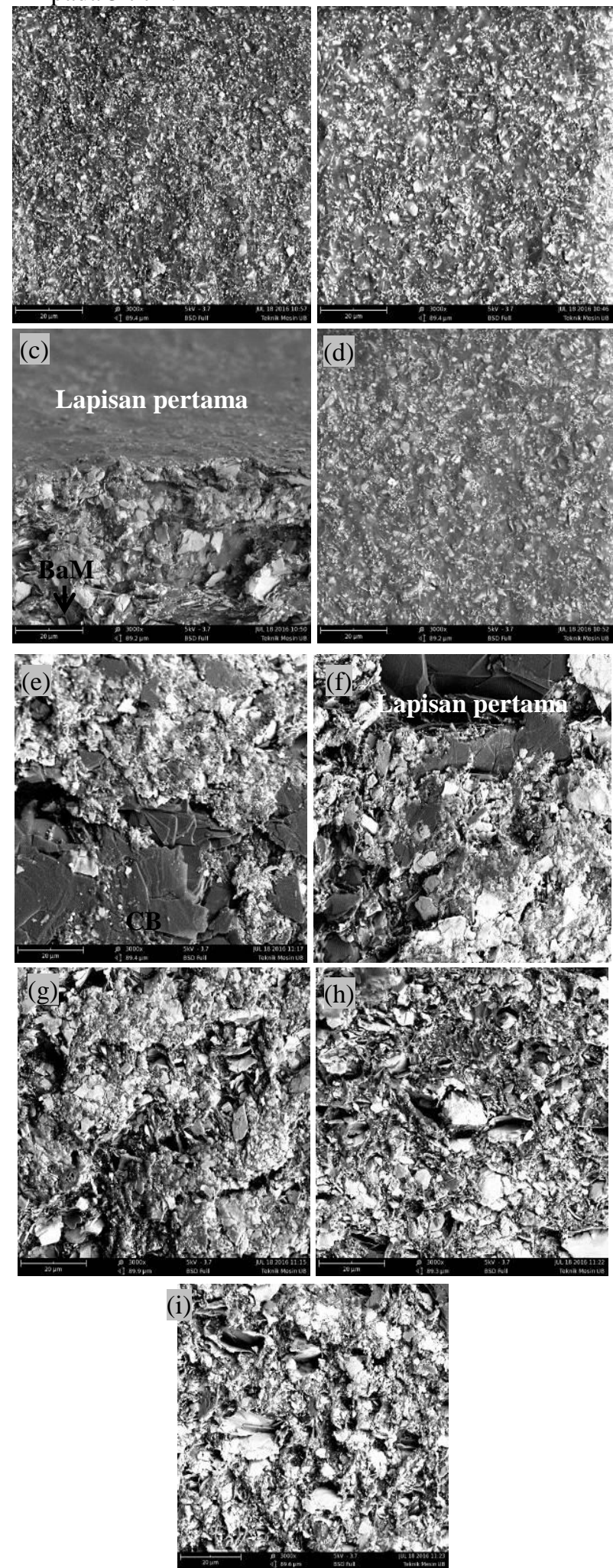

Gambar 2. Hasil Pengujian SEM Perbesaran 3000x (a) Single layer, (b) lapisan pertama double layer, (c) batas lapisan pertama dan lapisan kedua double layer (d) lapisan kedua double layer, (e) lapisan pertama multilayer, (f) batas lapisan pertama dan lapisan kedua multilayer, (g) lapisan kedua multilayer, (h) batas lapisan kedua dan ketiga multilayer dan (i) lapisan ketiga multilayer.

Distribusi komposisi partikel yang terdapat pada komposit BaM/PAni dianalisa menggunakan EDX. Analisa ini dilakukan pada area tertentu sehingga didapatkan komposisi secara umum. Hasil EDX ditunjukkan pada Gambar 3.

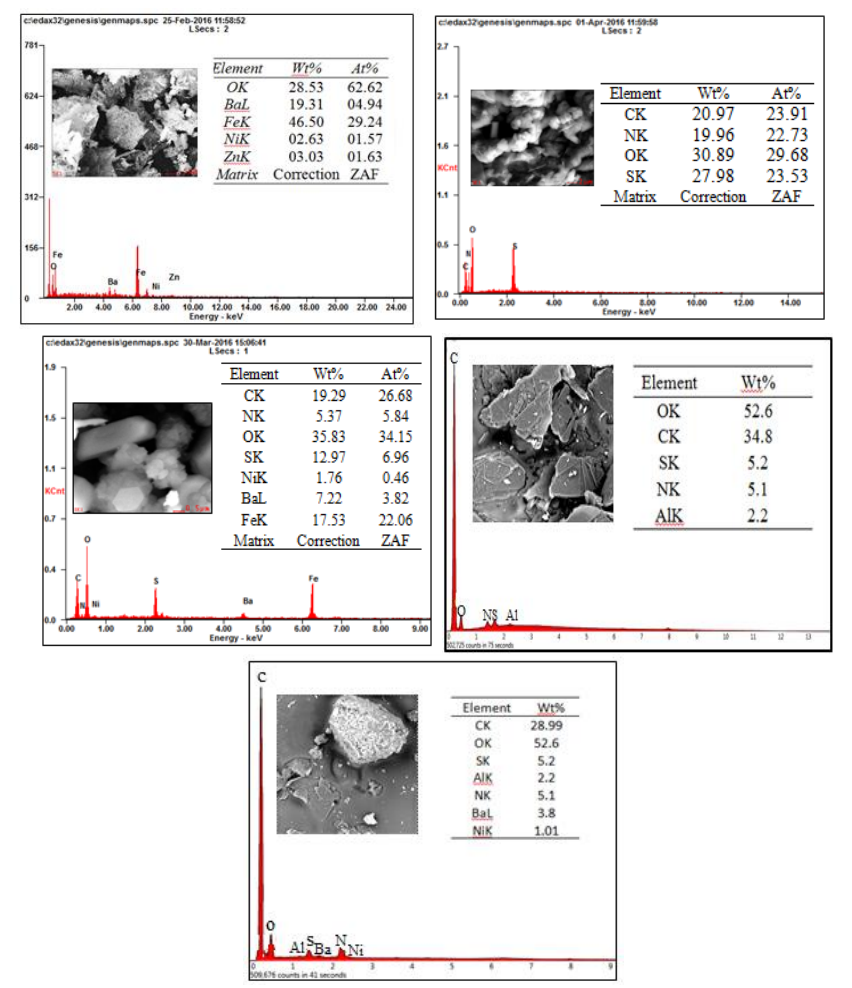

Gambar 3. Hasil Pengujian EDX (a) BaM perbesaran 2000x, (b) PAni perbesaran 2000x (c) BaM/PAni perbesaran 20000x (d)Carbon black perbesaran 2000x dan (e) BaM/PAni + CB perbesaran 1000x.

Pada hasil pengujian EDX tersebut, muncul unsur $\mathrm{C}, \mathrm{O}$, $\mathrm{N}, \mathrm{Ba}, \mathrm{Fe}, \mathrm{Ni}$ dan $\mathrm{Zn}$ pada pengujian sampel BaM/PANi. Dimana hal ini menunjukkan bahwa telah terbentuknya komposit BaM/PAni, dimana unsur $\mathrm{C}, \mathrm{O}$ dan $\mathrm{N}$ merupakan unsur yang terbentuk pada polimer PAni. Dan pada Gambar 3e muncul unsur $\mathrm{C}, \mathrm{O}, \mathrm{S}, \mathrm{Al}, \mathrm{N}, \mathrm{Ba}, \mathrm{Ni}$.

\section{B. Hasil Pengujian FTIR}

Pengujian ini dilakukan dengan tujuan untuk mengetahui ikatan-ikatan yang ada pada polimer (PAni), BaM, CB, untuk mengetahui adanya kandungan $\mathrm{BaM}$ pada komposit BaM/PAni yang telah dibuat dan ikatan pada komposit $\mathrm{BaM} / \mathrm{PAni}$ yang telah ditambahkan $\mathrm{CB}$. Hasil pengujian FTIR untuk sampel PAni dan komposit BaM/PAni ditunjukkan oleh Gambar 3. Dari grafik tersebut diperoleh sejumlah peak yang dapat digunakan untuk mengidentifikasi ikatan-ikatan apa saja yang terdapat pada PAni (Gambar 3a) dan adanya ikatan lain pada komposit BaM/PAni (Gambar 4b) . Untuk mengkonversikan peak-peak pada grafik hasil pengujian FTIR menjadi keterangan ikatan, dapat diperoleh dari data tabel yang terdapat di Handbook FTIR, sehingga diperoleh Tabel 1. Jumlah dan ketinggian peak pada grafik pengujian FTIR kedua sampel tidak jauh berbeda, namun pada komposit PAni/BaM ditemukan adanya ikatan M-O pada 532, 478, 466, $429 \mathrm{~cm}^{-1}$, dimana ikatan tersebut menunjukkan bahwa adanya ikatan logam pada sampel yang diuji. Ikatan logam tersebut merupakan ikatan dari BaM dengan oksigen dari polimer. Sehingga, dapat disimpulkan bahwa proses pembuatan komposit berhasil dengan adanya ikatan antara BaM dengan PAni pada komposit BaM/PAni. 


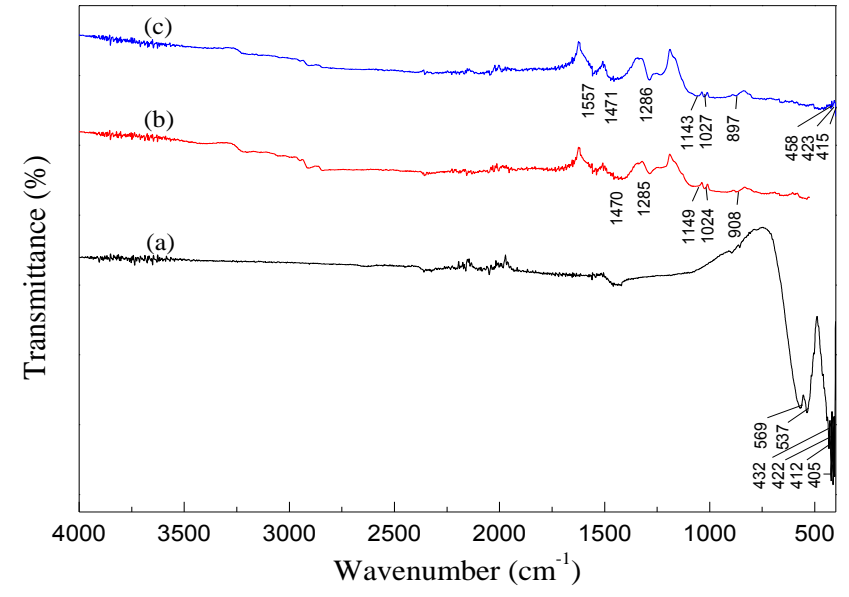

Gambar 4. Hasil FTIR pada (a) BaM (b) PAni dan (c) Komposit BaM/PAni.

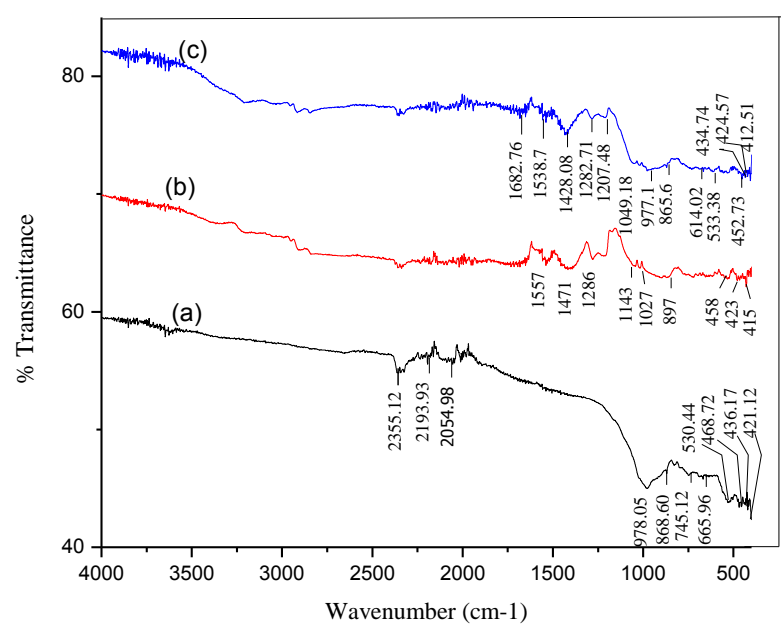

Gambar 5. Hasil FTIR pada (a) Carbon Black (b) Komposit BaM/PAni dan (c) Komposit BaM/PAni + CB.

Dari grafik tersebut diketahui bahwa CB memiliki peak pada wave number 978, 868, 745, 665, 530, 468, 436 dan $421 \mathrm{~cm}^{-1}$. Jumlah dan ketinggian peak pada grafik pengujian FTIR sampel komposit BaM/PAni dan sampel Komposit $\mathrm{BaM} / \mathrm{PAni}+\mathrm{CB}$ tidak jauh berbeda,

$\begin{array}{ccc}\mathrm{C}=\mathrm{C} \text { quinoid stretching } & 1557 & 1557 \\ \mathrm{C}=\mathrm{C} \text { benzene } & 1285 & 1286 \\ \text { stretching } & & \\ \mathrm{C}-\mathrm{N} \text { vibrasi } & 1149 & 1143 \\ \mathrm{~S}=\mathrm{O} \text { stretching } & & \\ \mathrm{N}=\mathrm{Q}=\mathrm{N}(\mathrm{Q} \text { adalah } \\ \text { quinoid) }\end{array}$

$\begin{array}{ccc}\text { C-H benzene deformasi } & 908 & 897 \\ \text { M-O } & - & 453,423,415\end{array}$

\section{Hasil Pengujian LCR-meter}

Hasil dari pengujian LCR-meter ini ditunjukkan oleh Tabel 2, dari tabel tersebut diketahui nilai konduktivitas listrik PAni sebesar $8.79809 \times 10^{-8} \mathrm{~S} / \mathrm{cm}$, konduktivitas listrik komposit BaM/PAni sebesar $1.77744 \times 10^{-5} \mathrm{~S} / \mathrm{m}$, konduktivitas listrik CB sebesar $3.89051 \times 10^{-3} \mathrm{~S} / \mathrm{cm}$ dan konduktivitas listrik komposit + CB sebesar 2.99134 x $10^{-2}$ $\mathrm{S} / \mathrm{cm}$.

Tabel 2

Konduktivitas Listrik material RAM.

\begin{tabular}{cc}
\hline \hline Material & Konduktivitas Listrik $(\mathrm{S} / \mathrm{cm})$ \\
PAni & $8.79809 \times 10^{-8}$ \\
BaM/PAni & $1.77744 \times 10^{-5}$ \\
CB & $3.89051 \times 10^{-3}$ \\
BaM/PAni + CB & $2.99134 \times 10^{-2}$ \\
\hline \hline
\end{tabular}

D. Hasil Pengujian VNA

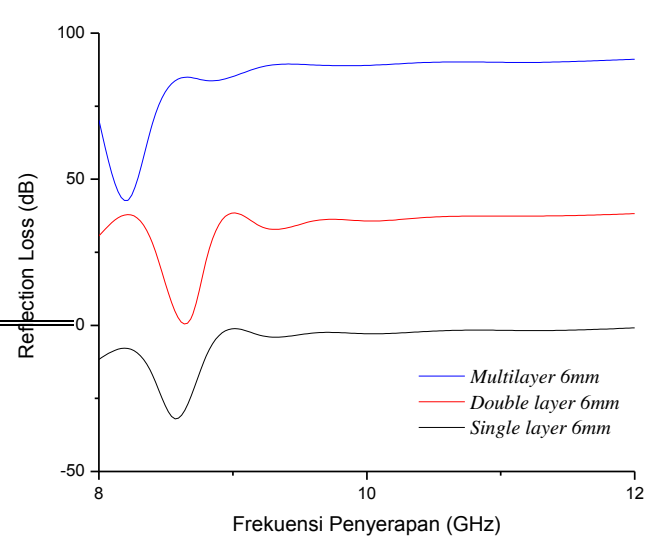

Gambar 6. Hasil Pengujian VNA Single Layer Double Layer dan Multilayer pada ketebalan $6 \mathrm{~mm}$.

Tabel 3

Rugi refleksi Radar Absorbing Material (RAM).

\begin{tabular}{ccc}
\hline \hline Jumlah lapisan & $\begin{array}{c}\text { Reflection } \\
\text { Loss }(\mathrm{dB})\end{array}$ & $\begin{array}{c}\text { Absorption band } \\
(\mathrm{GHz})\end{array}$ \\
\hline Cat epoxy & $-2,977$ & 8 \\
Single layer & $-32,029$ & 8,57 \\
Double layer & $-35,352$ & 8,7 \\
Multilayer & $-49,028$ & 8,2 \\
\hline \hline
\end{tabular}

Dari hasil pengujian VNA diketahui nilai reflection loss dari 3 sampel yang telah diuji (Tabel 3.), berdasarkan tabel tersebut nilai reflection loss terendah diperoleh dari sampel lapisan multilayer dengan ketebalan $6 \mathrm{~mm}$ sebesar $-49,028$ $\mathrm{dB}$ pada pita penyerapan $8,2 \mathrm{GHz}$, sedangkan nilai reflection loss tertinggi berasal dari sampel lapisan single layer dengan ketebalan $6 \mathrm{~mm}$ sebesar $-32,029 \mathrm{~dB}$ pada pita penyerapan 8,57 GHz. Dimana semakin negatif atau besar nilai reflection loss maka semakin besar pula daya serap material terhadap gelombang mikro [8]. 


\section{KESIMPULAN}

Dari penelitian yang telah dilakukan dapat diperoleh kesimpulan, bahwa:

Penyerapan optimum akibat pengaruh variasi jumlah lapisan dimiliki oleh jumlah lapisan multilayer dengan reflection loss sebesar $-49,028 \mathrm{~dB}$ pada frekunsi $8,2 \mathrm{GHz}$, diikuti dengan lapisan double layer dengan reflection loss sebesar $-35,352 \mathrm{~dB}$ pada frekunsi $8,7 \mathrm{GHz}$ dan terakhir lapisan single layer dengan reflection loss sebesar $32,029 \mathrm{~dB}$ pada frekunsi $8,57 \mathrm{GHz}$. Hal ini disebabkan oleh pengaruh adanya carbon black yang mempunyai nilai konduktivitas yang tinggi.

\section{DAFTAR PUSTAKA}

[1]Park, K.Y., Sang-Eui Lee, Chun-Gon Kim, Jae-Hung Han, (2006), "Fabrication and Electromagnetic Characteristics of Electromagnetic Wave Absorbing Sandwich Structures", Composites Science and Technology, Vol.66, hal.576-584.

[2]Wan, M., (2008), "Conducting polymers with micro or nanometer structure", Tsinghua University Press, Beijing.

[3]Nasution, E.L.Y., dan Astuti, (2012), "Sintesis Nanokomposit PAni $/ \mathrm{Fe}_{3} \mathrm{O}_{4}$ Sebagai Penyerap Magnetik Pada Gelombang Mikro", Jurnal Fisika Unand, Vol. 1, No. 1, hal.37-44.

[4]HaoTing, T., and Kuo-Hui, Wu., (2010), "Synthesis, characterization of polyaniline $/ \mathrm{BaFe}_{12} \mathrm{O}_{19}$ composites with microwave-absorbing properties", Journal of Magnetism and Magnetic Materials, Vol.322, hal.2160-2166.

[5]Amalia, L., (2014), Pelapisan Double Layer dengan Metode Dallenbach Layer Menggunakan Polianilin dan Barium MHeksaferit Sebagai Radar Absorbing Material (RAM). Tesis S2 Jurusan Fisika FMIPA, ITS, Surabaya

[6]Nuraini, U., (2015), Pelapisan Multilayer dengan Menggunakan Polianilin dan Hematit sebagai Radar Absorbing Material (RAM)", Tesis S2 Jurusan Fisika FMIPA, ITS, Surabaya.

[7]Jiang J., L-Hong Ai, Lin-Y.L., (2010), "Poly(aniline-co-otoluidine)/ $\mathrm{BaFe}_{12} \mathrm{O}_{19} \quad$ composite: Preparation and characterization", Materials Letters, Vol.64, hal.888-890.

[8]Phang, S.W., Tadakoro, M., Watanabe, J,dan Kuramoto, N. 2008. "Synthesis, Characterization and Microwave Absorbtion Property of Doped Polyaniline Nanocomposite Containing TiO2 Nanoparticles and Carbon Nanotube,"Synthetic Metals, No.158, hal. 251-258. 